Irrigation and Drainage Systems 10: 281-294, 1996.

(C) 1996 Kluwer Academic Publishers. Printed in the Netherlands.

\title{
Quality and maximum profit of industrial tomato as affected by distribution uniformity of drip irrigation system
}

\author{
FRANCISCO L. SANTOS \\ Departamento de Engenharia Rural, Universidade de Évora, Apartado 94, 7001 Évora \\ Codex, Portugal
}

Accepted 2 December 1995

\begin{abstract}
The tomato industry reformed its system of payment by weight of tomato, introducing a corrective system based on percent level of fruit dry matter produced. Such a decision implies significant changes in the management of irrigation systems, with a need to emphasize the technological quality of the marketable product. Three levels of distribution uniformity of the irrigation system are analysed, and related production functions of crop yield and percent of dry matter are presented as well as their use on the optimisation of dry matter, expected revenues and seasonal applied water. Results are critically influenced by the distribution uniformity. They demonstrate the inter-relationship between crop production, percent fruit dry matter and irrigation management, and the importance of considering non-uniformity in the economic analysis of industrial tomato production. Decreases in uniformity lead to a reduction in dry matter production per unit land. Decreases in dry matter are also observed with increasing levels of seasonally applied water, with the optimal level always lower than the required for maximum yield. Such interaction suggests a continuous and inverse relationship between profit and water applied. However, due to the corrective system of payment, by levels of percent of dry matter produced, for some uniformity, the expected revenue follows the yield-water production function instead of the dry matter function. This fact introduces disturbances in the optimal water applied inducing higher than expected levels of water applied for profit maximisation. The simulated data also show that incentives to switch to new systems or management practices able to raise the distribution uniformity result more from profit losses than increases in water price.
\end{abstract}

Key words: tomato crop-water production function, distribution uniformity, quality of tomato, dry matter

\section{Introduction}

Efficient use of irrigation water, yield increases and potential for higher income are pushing farmers in Portugal to adopt high frequency irrigation systems for the production of tomatoes (Lycopersicon esculentum Mill) for industry (Calado 1991), despite the high initial costs of installation. The system is used daily or several times per week to satisfy the crop water needs and obtain the maximum possible yields.

Water application is a management decision which controls, subject to several alternatives, inflow rate, time of application, total water volume and, 
indirectly, the crop growth. When the distribution of infiltrated water is uniform over the entire field there exists a potential to give the exact amount of water to satisfy the crop needs and obtain the maximum production possible. This method is adequate for most crops and for those whose commercial quality of the final product is not affected by high level of soil water. Drip irrigation field experiments with the industrial tomato (Calado 1991) showed that increasing levels of water application resulted in yield increments but decreased the marketable quality of the fruit with reductions in sugar content and in the percent of soluble dry matter of the harvested fruit $\left({ }^{\circ}\right.$ Brix).

The industry has traditionally valued tomatoes by the kilo of produce and only recently, with a mandatory norm from the European Community (C.E.E. 1991), a corrective system has been introduced in Portugal for payments to be done according to the ${ }^{\circ} \mathrm{Brix}$ of the fruit. The norm set the payments by ranking class of produced ${ }^{\circ}$ Brix. This shift toward the technological quality of the harvested product forces the farmer to a different management of his irrigation system. The interdependency between total yield and ${ }^{\circ} \mathrm{Brix}$, and the decreasing quality of marketable fruits with high levels of applied water, will require the optimisation of tomato water application. Evaluations by Letey et al. (1984) and Sammis \& Wu (1985) of crop water application and the effects of optimal levels of applied water on profitability of irrigation suggest taking into account the distribution uniformity of the irrigation system.

Non-uniform water distributions of high frequency irrigation systems are the result of different emitter flow rates, function of hydraulic design of the system and emitter manufacturing characteristics, clogging and temperature variations. The effect of non-uniformity is the same despite the cause, but it affects the optimal yield, and the seasonal amount of water applied (Seginer 1978; Santos 1990). Due to the flow rate variations some areas of the field are irrigated in excess and others in deficit. In the case of the industrial tomato, it is expected that in the areas of the field with excess water there is a total crop yield and fruit dry matter reduction and water percolation under the root zone, with additional costs in irrigation water. Meanwhile, in the deficit water areas, a reduction in the tomato crop yield production is expected, but with substantial increases in the technological quality of produced fruits and water savings.

Crop water production functions are usually derived from field plots and they imply uniform water application across the field. Situations are usually very different in farmers' fields where the depth of applied water may vary considerably with location (Seginer 1978; Warrick \& Yates 1987). Thus, field-level production functions may differ from those estimated assuming uniform irrigation. Letey et al. (1984) presented a very flexible method to integrate crop-water production functions with a spatial variability of applied 
and infiltrated water. In this study we use the method to analyse the production of the industrial tomato, expanded to incorporate the analysis of the technological quality of the harvested product. A set of crop yield water-uniformity response curves which account for non-uniformity of irrigation and simulated inter-relationships between crop production, fruit dry matter, revenue and applied water, as affected by distribution uniformity of the irrigation system, are presented.

\section{Materials and methods}

Crop water requirement is related to the radiant solar energy not used in the photosynthetic process or reflected by the earth surface but in evapotranspiration (ET), inducing crop transpiration and soil water evaporation (Doorenbos \& Pruitt 1984). The purpose of irrigation is to meet the evapotranspiration demand by an adequate application of water. Since the experimental work of Stewart et al. (1973) showing the close relationship between crop yield and evapotranspiration, a large body of literature has demonstrated this dependency. The characterisation of crop response to input of water has become widely known as a crop-water production function (Hexem \& Heady 1978) and it has been used since then in research, crop yield prediction, economic evaluation of irrigation management and mathematical programming, to determine farmer profit-maximising enterprise combinations (Doorenbos \& Kassam 1979; Barrett \& Skogerboe 1980; Hazell \& Norton 1986). The limitations of these empirical relationships are their lack of transportability and confidence to predict what might happen in other locations. To extend the functions for use in other sites Stewart et al. (1973) and Doorenbos \& Kassam (1979) proposed a functional form expressed in relative terms to relate yield reduction to percent evapotranspiration deficit as:

$$
E T / E Y_{m}=\left[1-B_{e}\left(1-E T / E T_{m}\right)\right]
$$

where:

$$
\begin{aligned}
\mathrm{EY}_{m}= & \text { the maximum economic yield in } \mathrm{Mg} / \mathrm{ha} \\
\mathrm{ET}_{m}= & \text { the maximum evapotranspiration in } \mathrm{mm} \\
\mathrm{B}_{e}= & \text { the proportionality factor, which indicates the sensitivity of the } \\
& \text { crop yield to water deficits, between }\left[1-\left(E Y / E Y_{m}\right)\right] \text { and } \\
& {\left[1-\left(E T / E T_{m}\right)\right] . }
\end{aligned}
$$

Yields are expressed on a relative basis with the value of 1.0 representing maximum yield and seasonal values of water applied are scaled by seasonal maximum crop evapotranspiration, to adjust for climatic conditions and allow 
for transfer among geographical areas of different climates and growing conditions.

To relate a specific crop production function to the distribution uniformity of the irrigation system, a knowledge of the field uniformity is required, as well as the seasonal amount of applied and infiltrated water in different sections of the irrigated field. The distribution uniformity of high frequency irrigation systems is usually related to a statistical uniformity coefficient $\left(\mathrm{U}_{S}\right)$, based on the coefficient of variation of the emitter flow rate. According to Bralts et al. (1981).

$$
U_{S}=1-V_{T}
$$

where $\mathrm{V}_{T}=$ coefficient of variation of emitter flow.

The distribution of infiltrated water paired with the experimental crop yield (or ${ }^{\circ}$ Brix) production function makes it possible to obtain the contribution of each section of the irrigated field to total yield and total fruit dry matter. Hill and Keller (1980) partially illustrate the procedure. If the seasonal water distribution function is $\mathrm{f}(\mathrm{w})$ and $\mathrm{y}(\mathrm{w})$ is the yield for a given water application (the yield or dry matter function), the expected yield, $\bar{Y}$ is:

$$
\bar{Y}=\int_{0}^{\infty} y(w) f(w) d w
$$

$\mathrm{Y}(\mathrm{w})$ is usually the yield-ET production function suggested by Stewart et al. (1973). For convenience, the seasonal water distribution can be represented by a discrete function and the associated yield calculated as:

$$
\bar{Y}=\sum_{i=1}^{m} P_{i} y\left(w_{i}\right) A_{i}
$$

where $A_{i}$ is the area in the $\mathrm{i}^{\text {th }}$ section of the field, $\mathrm{m}$ is the total number of area increments of the field, $\mathrm{P}_{i}$ is the percentage of land receiving $\mathrm{w}_{i}$ depth of irrigation water, $\mathrm{w}_{i}$ is the depth of application received by the $\mathrm{i}^{\text {th }}$ area increment and $y$ is the functional relationship between yield and depth of applied water. The procedure requires detailed knowledge of applied and infiltrated water in each section of the irrigated field and the specific cropwater production function.

\section{Procedure}

Three coefficient of variation $\left(\mathrm{V}_{T}\right)$ of water applied by the irrigation system were selected for the analysis. $0.10,0.20$ and 0.30 were considered when 
looking for the range of values found in high frequency irrigation, usually designed for $\mathrm{V}_{T}$ of 0.20 . These selected values correspond to Christiansen uniformity coefficient (CUC) of $0.92,0.84$ and 0.76 respectively, related to $\mathrm{V}_{T}$ by $\mathrm{CUC}=1-0.8 \mathrm{~V}_{T}$ (Warrick 1983).

Studies of testing normality of drip irrigation emitter flow (Solomon 1979; Wu \& Gitlin 1983; Clemmens 1987; Wu 1988) showed that the emitter flow can be represented as a normal distribution. Based on the normal distribution of Hart and Reynolds (1965) and on the crop maximum evapotranspiration, the area irrigated was divided into equal increments (field sections) and for each CUC, the average depth of application, the ratio of the depths received in each area increment to the average depth applied, and the spatial distribution of the infiltrated depths were calculated. Crop yield and percentage of harvested fruit dry matter-uniform water production functions of the cultivar Rio Grande reported by Calado (1991) were selected to obtain the contribution of each section of the irrigated field to total yield and ${ }^{\circ} \mathrm{Brix}$, by matching the calculated depths of infiltrated water to the production functions. Figure 1 shows these simulated relationships for $\mathrm{CUC}=0.92$ and 62.5 percent of area adequately irrigated. The required input for the simulated field mean expected yield, ${ }^{\circ}$ Brix and applied water are shown below:

$\begin{array}{ll}\text { Maximum evapotranspiration } & 478.1 \mathrm{~mm}^{-1} \\ \text { Maximum crop yield } & 105.3 \mathrm{ton} \mathrm{ha}^{-1} \\ \text { Seasonal average applied water } & 481.1 \mathrm{~mm}^{-1} \\ \text { Marketable mean crop yield } & 101.3 \mathrm{ton} \mathrm{ha}^{-1} \\ { }^{\circ} \text { Brix corresponding to maximum yield } & 4.06 \\ \text { Average }{ }^{\circ} \text { Brix } & 4.10 \\ \text { Average harvested fruit dry matter } & 4.16 \mathrm{ton} \mathrm{ha}^{-1}\end{array}$

The same procedure can be used for each uniformity level and each assumption of fraction of area adequately irrigated.

\section{Results and discussion}

The relationships between the simulated industrial tomato yield, average seasonal applied water and distribution uniformity are presented in Fig. 2. The crop yield is higher for the CUC $=0.92$ for all levels of applied water. The shape of the yield function is the same for the other two uniformity levels but with lower crop yields. Increasing non-uniformity leads to decreases in yield, which is explained by higher deviations of the applied water values in each fraction of the field about the mean applied water. The deviations result in higher crop yield losses in each site and lower mean yield. The decrease 


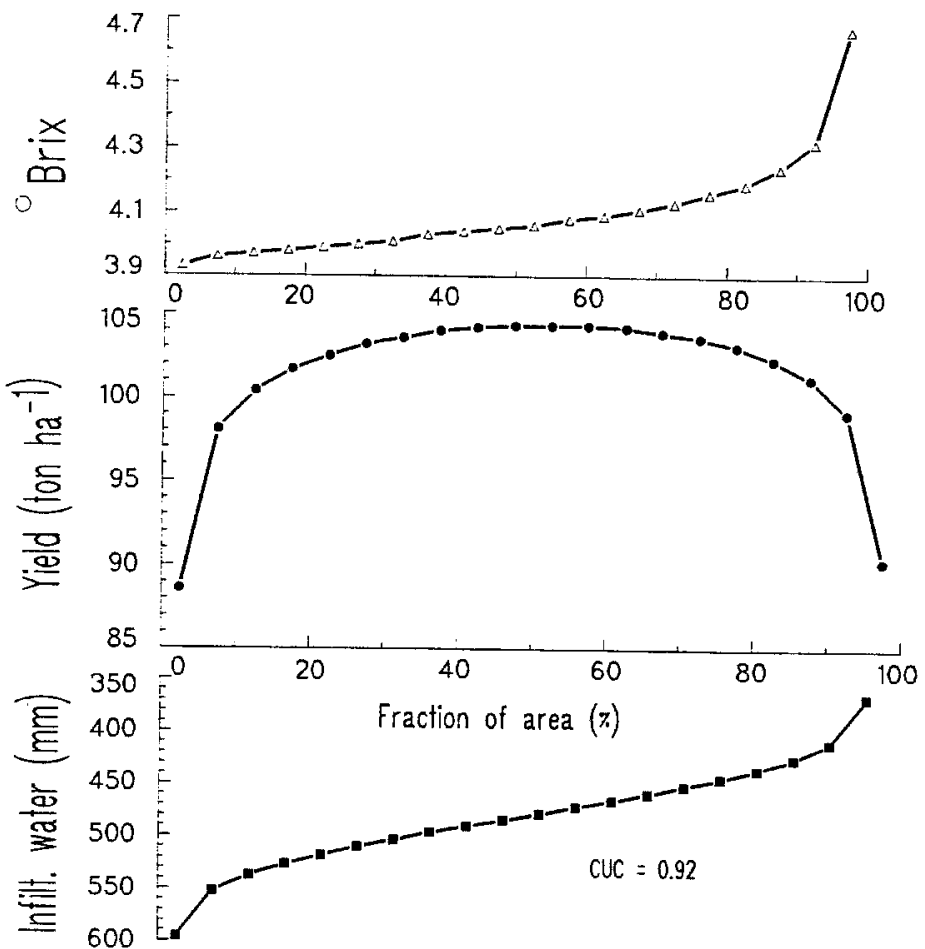

Figure 1. Simulated relationships for 0.92 uniformity and 62.5 percent of the area adequately irrigated.

in yield cannot be offset by increasing water application due to the quadratic nature of the water yield relationship.

The effects of different levels of distribution uniformity and average seasonal applied water on ${ }^{\circ}$ Brix produced are also illustrated in Fig. 2. Unlike yield, ${ }^{\circ}$ Brix increases with decreasing distribution uniformity and water application. The results indicate that higher fruit quality (higher ${ }^{\circ} \mathrm{Brix}$ ) is obtained with reductions in the seasonal water applied to obtain maximum crop yields. These higher values also reveal the direct relationship between the percentage of harvested fruit dry matter and higher levels of water stress, and illustrate the need for an irrigation management zeroed towards a delicate balance between crop yield production and fruit dry matter.

The preference assigned to the technological quality of the harvested product by the tomato industry forces the farmer to a different management of the irrigation system given that high quality, obtained with increasing levels of water stress, also reduces total yield. In these cases the optimisation of tomato water application requires the concurrent knowledge of crop-yield and ${ }^{\circ} \mathrm{Brix}$ 


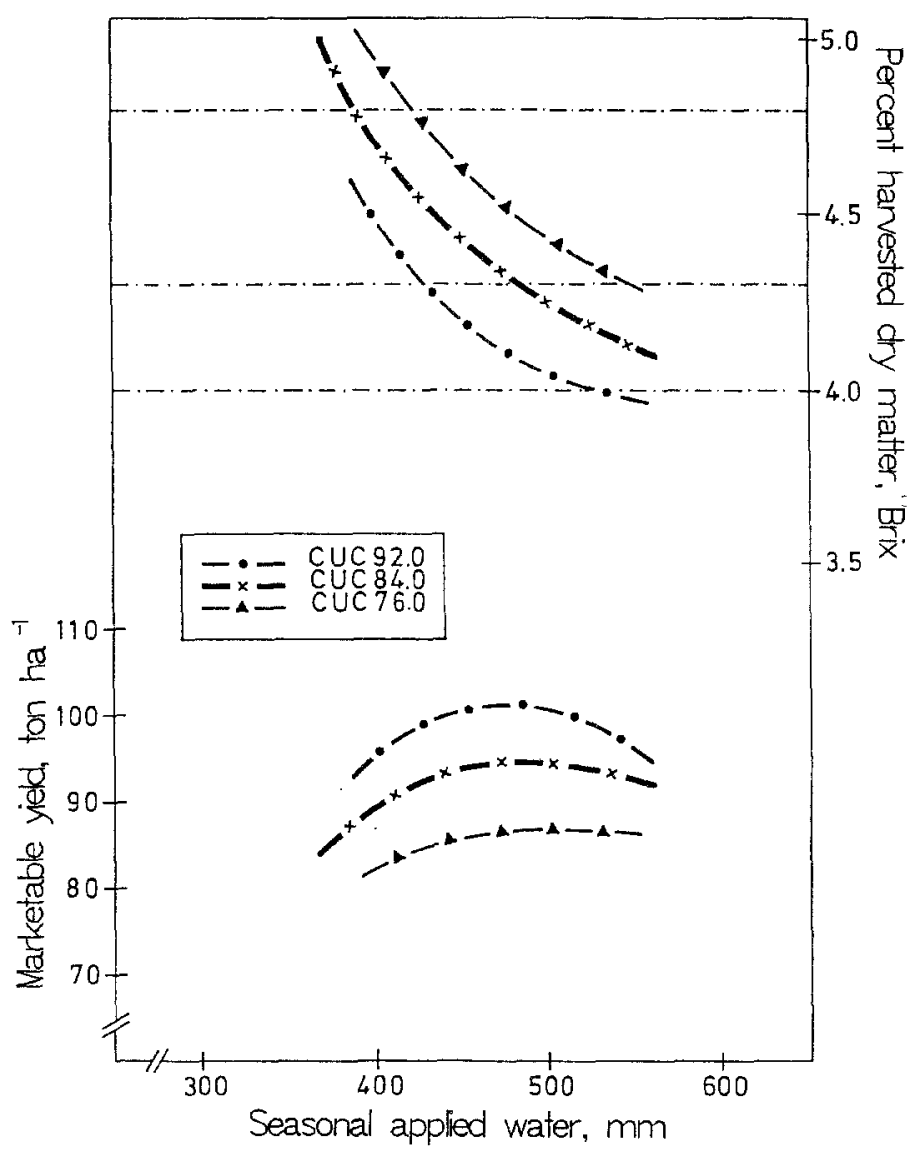

Figure 2. Influence of distribution uniformity and seasonal applied water on fruit yield and quality.

water production functions, both related to the distribution uniformity of the irrigation system. To obtain such functions suitable predictive equations were developed. Simulations similar to the one presented in Fig. 1 were derived for all distribution uniformities and the results were fitted, using the method of least squares and non-linear optimisation (Boratto 1984), to defined equation forms. Table 1 summarizes the parameters of the best fit productions obtained. The general form of the crop yield water-uniformity production functions is given by:

$$
Y / Y_{m}=a+b\left(w / w_{m}\right)+c\left(w / w_{m}\right)^{2}
$$

where 
Table 1. Parameters of field level crop-water production functions which account for non uniformity of irrigation.

\begin{tabular}{lccc}
\hline & \multicolumn{2}{c}{ Parameters } & \\
\cline { 2 - 4 } Marketable yield $^{1}$ & $\mathrm{a}$ & $\mathrm{b}$ & $\mathrm{c}$ \\
\hline Uniform & -1.4833 & +4.9655 & -2.4833 \\
CUC 92.0 & -1.2075 & +4.3537 & -2.1829 \\
CUC 84.0 & -0.7054 & +3.1273 & -1.5223 \\
CUC 76.0 & -0.1920 & +1.9313 & -0.9135 \\
\hline
\end{tabular}

\begin{tabular}{lrcl}
\hline $\begin{array}{l}\text { Percent dry matter } \\
\left({ }^{\circ} \text { Brix }\right)^{2}\end{array}$ & $\mathrm{a}$ & $\mathrm{b}$ & $\mathrm{c}$ \\
\hline Uniform & -8.8419 & +10.1927 & -0.03460 \\
CUC 92.0 & -17.2642 & +18.6739 & -0.022108 \\
CUC 84.0 & -8.6297 & +10.2324 & -0.05293 \\
CUC 76.0 & -18.5308 & +20.1870 & -0.02677 \\
\hline
\end{tabular}

${ }^{1} \mathrm{Y} / \mathrm{Y}_{m}=\mathrm{a}+\mathrm{b}\left(\mathrm{w} / \mathrm{w}_{m}\right)+\mathrm{c}\left(\mathrm{w} / \mathrm{w}_{m}\right)^{2}$

${ }^{20} \mathrm{~B} /{ }^{\circ} \mathrm{B}_{m}=\mathrm{a}+\mathrm{b} \operatorname{EXP}\left(\mathrm{c} \times \mathrm{w} / \mathrm{w}_{m}\right)$

$\mathrm{Y}=$ crop yield, ton/ha

$\mathrm{Y}_{m}=$ maximum yield with uniform systems, ton/ha

$\mathrm{w}$ = seasonal water, $\mathrm{mm}$

$\mathrm{w}_{m}=$ seasonal water applied for maximum yield, $\mathrm{mm}$

while the relative percent of ${ }^{\circ} \mathrm{Brix}$ is specified as:

$$
{ }^{\circ} B /{ }^{\circ} B_{m}=a+b \times E X P\left(c \times w / w_{m}\right)
$$

where:

$$
\begin{aligned}
{ }^{\circ} \mathrm{B}= & \text { harvested fruit dry matter, } \% \\
{ }^{\circ} \mathrm{B}_{m}= & \text { harvested dry matter for maximum yield, } \% \\
\mathrm{w}^{\mathrm{W}}= & \text { seasonal water applied, mm } \\
\mathrm{w}_{m}= & \text { seasonal water applied for }{ }^{\circ} \mathrm{B}_{m}, \mathrm{~mm} \\
& \mathrm{a}, \mathrm{b}, \mathrm{c}, \text { constants }
\end{aligned}
$$

The marketable and fruit dry matter crop production-uniformity functions are presented in dimensionless form to allow for generalisation to areas of different climates and growing conditions. The uniform functional relationships are also included to make way for calculation of production functions based on distribution uniformities other than the ones presented.

Figure 3 illustrates the interaction between total yield and ${ }^{\circ}$ Brix (Fig. 2) and their contribution to total harvested dry matter per unit land. More uniform 


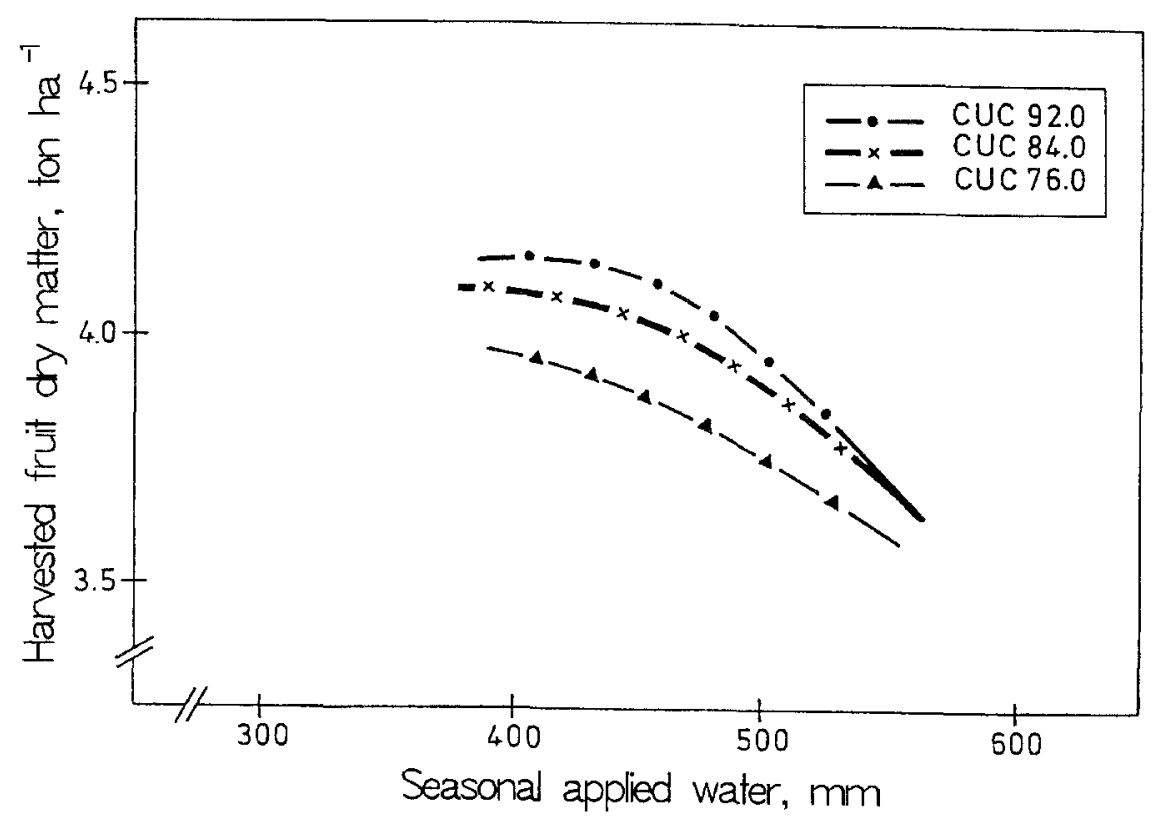

Figure 3. Interaction between seasonal applied water and total harvested dry matter.

irrigation systems show higher levels of dry matter and, for all uniformities, the optimal water applied further deviates from the maximum yield water levels. These stimulated results suggest the importance of adequate information on optimal applied water for management options. The inter-relationship between production and irrigation management in Table 1 provides information for such an optimisation. The results presented can be used to simulate the inter-relationship between crop production, percentage fruit dry matter and irrigation management which are important in the economic analysis of industrial tomato production management.

Economically, optimal values of a production factor such as water is better obtained by assuming profit maximizing behaviour (Cashwell \& Zilberman 1985). The optimal applied water level depends upon crop revenues and the price of water. Figure 4 presents the expected revenues calculated with a baseprice of 18.7 Esc per $\mathrm{kg}$ of marketable yield, corrected to take into account the percent of fruit dry matter (Table 2) and an average irrigation water price of 450 Esc per ha-mm. The results are critically influenced by the distribution uniformity. Decreases in uniformity lead to revenue reduction for the same applied water. The effects of changes in the quantity of applied water required 


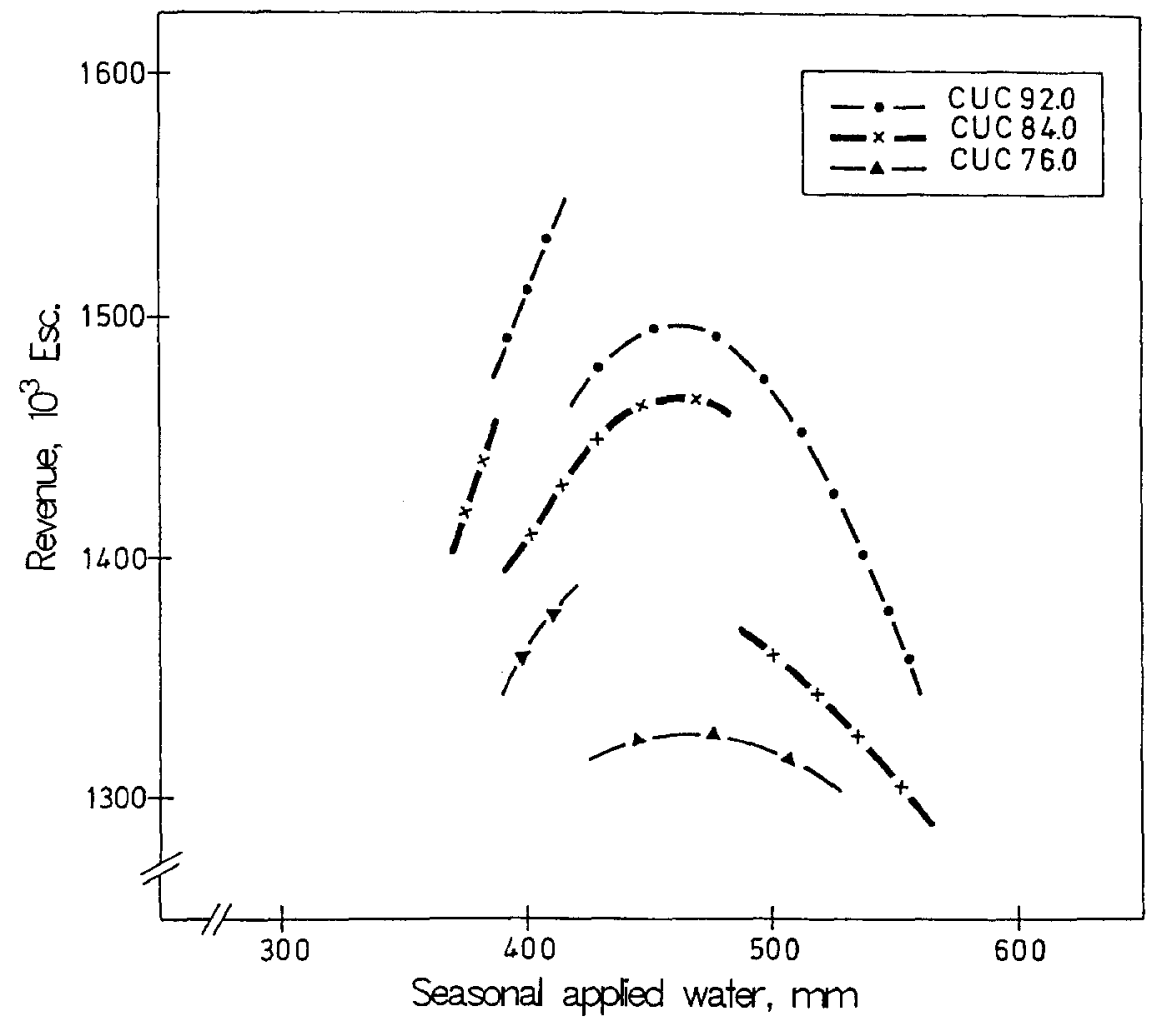

Figure 4. Revenue of industrial tomatoes as a function of seasonal applied irrigation water.

Table 2. Implemented percent fruit dry matter limits for correction of industrial tomato base-price.

\begin{tabular}{lc}
\hline Percent dry matter $\left({ }^{\circ}\right.$ Brix $)$ & Base-price correction (\%) \\
\hline 4.0 to 4.3 & -10.0 \\
4.3 to 4.8 & -5.0 \\
4.8 to 5.4 & base-price \\
4.8 to 5.8 & +5.0 \\
$>5.8$ & +10.0 \\
\hline
\end{tabular}

for maximum revenue are illustrated, showing optimal levels of application always lower than the requirement for maximum crop yield.

Even though the harvested fruit dry matter increases with decreasing applied water, which suggests a continuous and inverse relationship between revenue and water application, the new corrective payment system of the 
industrial tomato by intervals of ${ }^{\circ}$ Brix, is inadequate to set the optimal seasonal water application for all distribution uniformities. In the break intervals, shown by the dashed lines in Fig. 2, the revenue curves display discontinuities in Fig. 4, while in-between the intervals, where no payment differences for ${ }^{\circ}$ Brix occur, the decrease in total crop yield offsets the gains in harvested dry matter, generating lower revenues. This fact introduces disturbances in the optimisation of applied water. This is illustrated for the 0.84 distribution uniformity where between 4.3 and $4.8^{\circ} \mathrm{Brix}$, a wide range without payment increments, the decrease in yield offsets the percentage gain in dry matter not remunerated, resulting in lower revenues, and in water application for profit maximization higher than anticipated. A corrective payment norm based on unit increments of ${ }^{\circ} \mathrm{Brix}$ would be a better alternative solution.

The impact of non-uniform water distribution on revenues is also presented in Fig. 5 for various water prices. Regardless of the water price revenue is not sensitive to its changes, suggesting that incentives to switch to new systems or management practices able to raise the distribution uniformity result more from revenue losses which occur from lack of adequate uniformity, and not from water prices.

\section{Conclusions}

The shift toward a higher technological quality of the harvested tomato, and the interdependency between total yield and ${ }^{\circ}$ Brix requires from the farmers a different drip irrigation management given that high quality, obtained with increasing levels of water stress, also reduced total yield. Unlike total yield, higher fruit quality (higher ${ }^{\circ} \mathrm{Brix}$ ) also increases with decreasing distribution uniformity and water application, requiring the optimisation of seasonal water application and the concurrent knowledge of crop-yield and ${ }^{\circ} \mathrm{Brix}$ water production functions.

The results of this study show that the marketable yield, percentage harvested dry matter, harvested dry matter per unit land, seasonal applied water and revenues are critically dependent on the distribution uniformity of the irrigation system. Higher fruit quality is obtained with reductions in the seasonal water applied and uniformity, while marketable yield decreases. This fact indicates the need for an irrigation management geared towards a delicate balance between crop yield production and fruit dry matter. The predictive equations established in Table 1 can be used to simulate the inter-relationship between crop production, percentage fruit dry matter and irrigation management, and set alternative tomato water application amounts. Moreover, the relationship between harvested dry matter fruit yield per unit land and distribution uniformity shows that optimal levels of seasonal applied water 


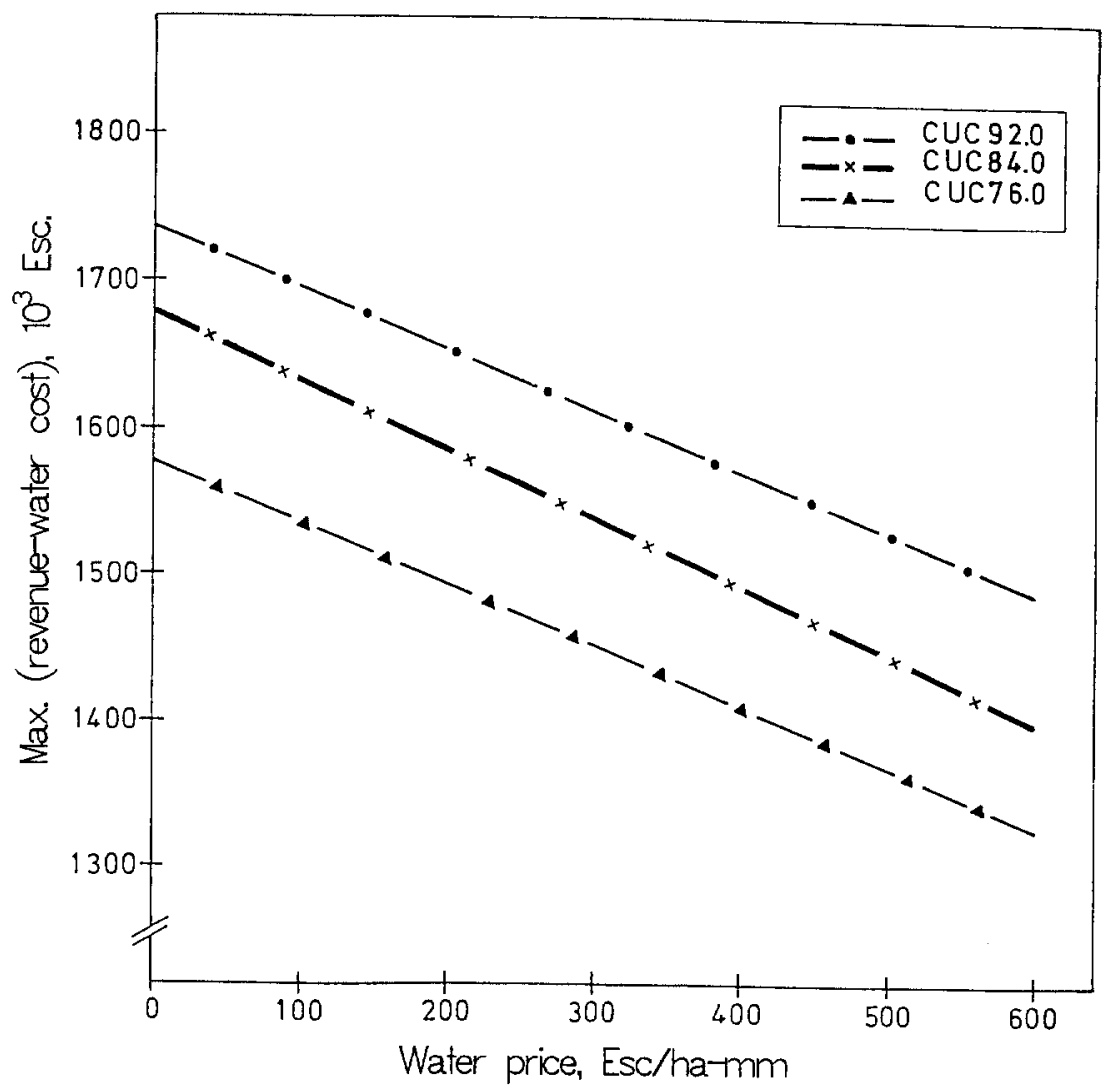

Figure 5. Impact of non-uniform water distribution on revenues for different water prices.

are always lower than the required for maximum yield, with higher yields obtained with more uniform systems.

The expected revenues calculated to take into account the percentage of fruit dry matter, by correcting the base-price per $\mathrm{kg}$ of marketable yield, and the average irrigation water price per ha-mm of applied water, show that decreases in uniformity lead to revenue reductions for the same applied water. Nevertheless, systematic reductions in the quantity of applied water show that revenue maximisation is obtained for applications always lower than the requirement for maximum crop yield.

Even though the results suggest a continuous and inverse relationship between revenue and water application, the new corrective payment system of the industrial tomato, by intervals of ${ }^{\circ} \mathrm{Brix}$, is inadequate to establish the optimal level of water application for all distribution uniformities. In the case 
of CUC $=0.84$, where between 4.3 and $4.8^{\circ}$ Brix the corrective payment system allows a wide range without revenue increments, the decrease in total crop yield offsets the percentage gain in dry matter, not remunerated, generating lower revenues. In this case, the water application level for profit maximisation is higher than anticipated from the yield $-{ }^{\circ}$ Brix relationship. For this frequently found field level drip irrigation uniformity, the corrective payment system induces a higher level of applied water, perpetuating the actual practice of excessive water application to obtain maximum crop production per unit land. To change the current practice, an alternative corrective payment norm based on unit increments of ${ }^{\circ}$ Brix should be considered.

Although an increase in water prices seems not to constitute enough incentive to raise the distribution uniformity, application of an amount of water lower than that required for maximum yield increases the application efficiency, and allows a substantial reduction in applied water and extension of the farm land under irrigation.

\section{References}

Barrett J.W.H. \& Skogerboe G.V. 1980. Crop production functions and the allocation and use of irrigation water. Agric. Water Manag. 3: 53-64.

Boratto F.J.M. 1984. BASIC para engenheiros e cientistas. Rio de Janeiro. Technical and Scientific Books. Ed. S.A.

Bralts V.F., Wu I.P. \& Gitlin H.M. 1981. Manufacturing variation and drip irrigation uniformity. Transactions of the ASAE 24(1): 113-119.

C.E.E. 1991. Regulations $n^{\circ}$ 2036/7. In: European Community Newsletter.

Calado A.M. 1991. Influence of localised irrigation on the physical production and quality of tomato for industry. (Translated from Portuguese.) Unpublished doctorate dissertation. Évora, Portugal: University of Évora.

Caswell M. \& Zilberman, D. 1985. The choices of irrigation technologies in California. American Journal of Agricultural Economics 67(2): 224-234.

Clemmens A.J. 1987. A statistical analysis of trickle irrigation uniformity. Transactions of the ASAE 30(1): 169-175.

Doorenbos J. \& Kassam A.H. 1979. Yield response to water. FAO Irrigation and Drainage Paper $\mathrm{N}^{\circ}$ 33, Food and Agriculture Organisation of the United Nations. Rome, Italy.

Doorenbos J. \& Pruitt W.O. 1977. Guidelines for predicting crop water requirements. FAO Irrigation and Drainage Paper $\mathrm{N}^{\circ} 24$, Food and Agriculture Organisation of the United Nations. Rome, Italy.

Hart W.E. \& Reynolds W.N. 1965. Analytical design of Sprinkler systems. Transactions of the ASAE 9(1): 83-85, 89.

Hazell P.B.R. \& Norton R.D. 1986. Mathematical Programming for Economic Analysis in Agriculture. Macmillan: New York.

Hexem R.W. \& Heady E.O. 1978. Water Production Functions and Irrigated Agriculture. Ames: Iowa State Univ. Press.

Hill R.W. \& Keller J. 1980. Irrigation system selection for maximum crop profit. Transactions of the ASAE 23(2): 366-372.

Letey J., Vaux Jr. H.J. \& Feinerman E. 1984. Optimum crop water application as affected by uniformity of water infiltration. Agron. J. 76: 435. 
Sammis T.W. \& Wu I.P. 1985. Effect of drip irrigation design and management on crop yield. Transactions of the ASAE 22(4): 832-838.

Santos F.L. 1990. Optimal irrigation system selection: a multiperiod quadratic programming approach. Unpublished Ph.D. dissertation. Tucson, Arizona: University of Arizona.

Seginer I. 1978. A note on the economic significance of uniform water application. Irrig. Sci. 1: 19.

Solomon K. 1979. Manufacturing variation of trickle emitters. Transactions of the ASAE 22(5): $1034-1038$.

Stewart J.I. \& Hagan R.M. 1973. Functions to predict effects of crop water deficits. J. Irrig. and Drain. Div. ACE 99: 421-439.

Warrick A.W. 1983. Interrelationships of irrigation uniformity terms. J. Irrig. Drain. Div. Am. Soc. Civ. Eng. 199: 317-332.

Warrick A.W. \& Yates S.R. 1987. Crop yield as influences by irrigation uniformity. Advances in Irrigation 4: 169-180.

Wu I.P. \& Gitlin H.M. 1983. Drip irrigation application efficiency and schedules. Transactions of the ASAE 26(1): 92-99.

Wu I.P. 1988. Linearized water application function for drip irrigation schedules. Transactions of the ASAE 31(6): 1743-1749. 